\title{
Health and Survival of Moon Jellies (Aurelia Aurita) in Hand-Built Pseudo-Kreisel Aquaria
}

\author{
Kathryn Schweizer ${ }^{a *}$, Christine Geiger ${ }^{\text {a }}$, Adam Pillot ${ }^{a}$, Melissa Meadows ${ }^{\text {a }}$ \\ ${ }^{a}$ Department of Biology, Saint Francis University, Loretto, Pennsylvania 15940, United States.
}

\begin{abstract}
Jellies are typically considered difficult organisms to raise in the lab by many scientists. This is due to their requirements for constant water current and the absence of corners. In the wild, jellies such as moon jellies (Aurelia aurita) rarely encounter habitats outside of the open ocean where they are part of the plankton, so they are not adapted to navigate obstacles or get out of small spaces such as the corners of aquaria. In order to conduct an experiment utilizing live moon jellies to assess their utility in bioremediation of oil spills, we designed and built 4 pseudo-kreisel aquaria to house our jellies using a limited budget and many readily-available materials. Here, we present the methods used to construct these aquaria inexpensively (important for undergraduate research!) and evidence of their effectiveness in long-term housing of live jellies so that other researchers interested in jelly research can construct similar housing. Briefly, we removed the corners from 10 gallon aquaria and also provided for continuous circular water currents by adding quarter pieces of the sides of 5 gallon buckets attached via silicon sealant. Current was provided by spray bars that provided even water flow in all areas of the aquaria, driven by pumps in the external sump and filtration systems. We built the sump/filtration systems using 5-gallon buckets containing bio-balls and filter floss. Water was delivered to the sumps via PVC overflow plumbed into the aquaria via a bulkhead set into the glass at the desired water level. The overflows were covered with a small piece of fine screen and directly behind the spray bars in order to prevent jellies from becoming stuck as water leaves the system for filtration. Results of husbandry including survival and indicators of jelly health such as pulsing rate and holes in their bells over approximately 3 months will be presented.
\end{abstract}

\section{Keywords:}

Moon Jellies;

Aurelia Aurita;

Pseudo-Kreisel;

Aquaria;

\section{Article History:}

Received: $30 \quad$ July 2018

Accepted: 27 September 2018

\section{1- System Design}

To build the system that houses the jellyfish, we used 4 ten-gallon aquaria and used plastic sheeting sealed to the sides of the aquaria to create a rounded bottom with no corners. As pelagic plankton, moon jellyfish get stuck in the corners of regular aquaria which is harmful to them. The rounded design also aids in circulation (along with a spray bar, described below), creating a continuous cylindrical water flow.

The filtration and circulation system was also hand-built. In each aquarium, we drilled a hole in the glass 3 inches from the top of the tank. There we attached a using a bulkhead and PVC pipe that feeds water exiting the tank into the external sump bucket under the table. This bucket is used for increased water volume, filtration, and circulation. A piece of plastic screen on the inside of the tank keeps the jellyfish from getting sucked into the drain. From the drain pipe, water passes through a filter pad and then a layer of bio balls. These bio balls have nitrifying bacteria that digest jellyfish waste and other particulates through filtration. A pump in the bottom of the bucket pumps water through a flexible hose and to the spray bar. The spray bar is made of PVC pipe with small holes drilled in a line along its length that washes the water in a flat sheet across the outside of the exit screen. This entire set-up cost only about $\$ 60$ per aquarium in new materials.

Salt water for the aquaria is made with Seachecm Vibrant Sea salt mixed at 35 ppt (parts per thousand). PH was maintained at 8.2 throughout the study.

\footnotetext{
*CONTACT: Kgs104@francis.edu

DOI: http://dx.doi.org/10.28991/esj-2018-01154
}

(C) This is an open access article under the CC-BY license (https://creativecommons.org/licenses/by/4.0/). 
To evaluate our success in keeping jellies at a bargain price, we measured water parameters and recorded health and survival of the jellies, focusing on aquarium 3 which had no oil added.

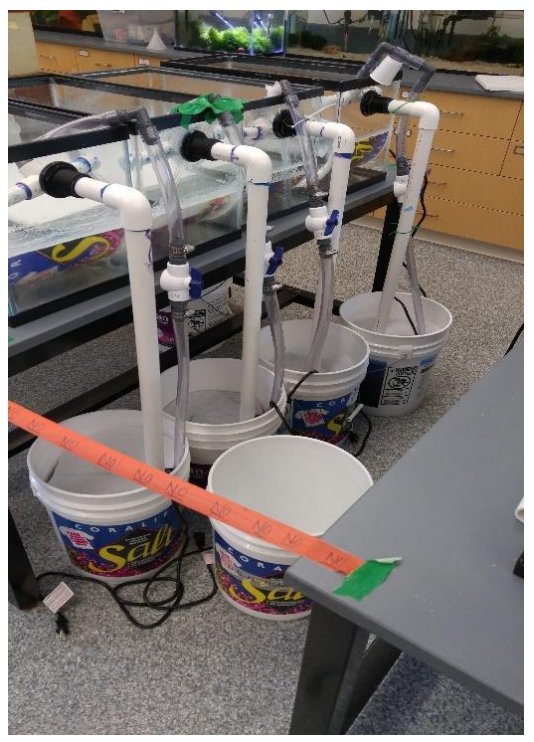

Figure 1. Portrays the plumbing system that goes from the tank to the buckets below.

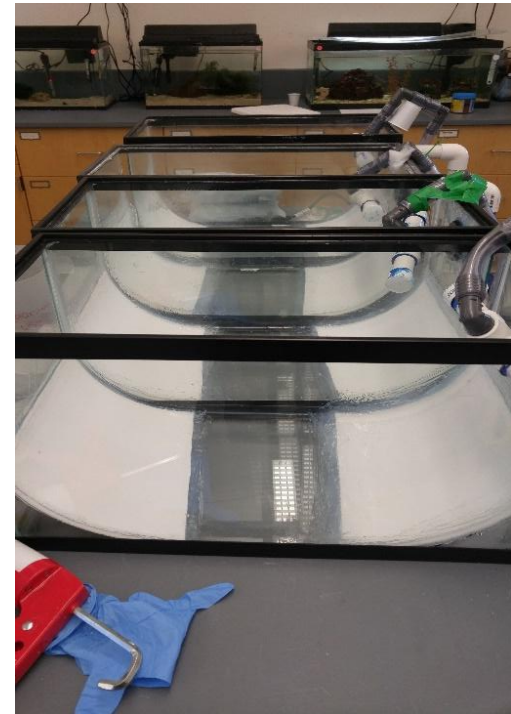

Figure 2. Pictures how the sides of the tank are curved.

\section{2- Results}

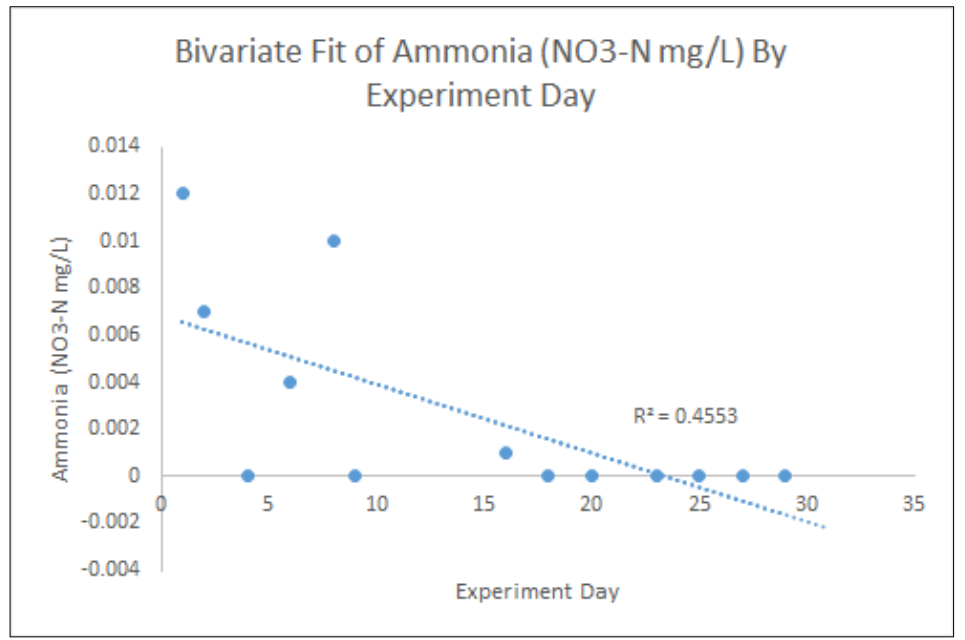

Figure 3. The correlation of ammonia to time shown in days.

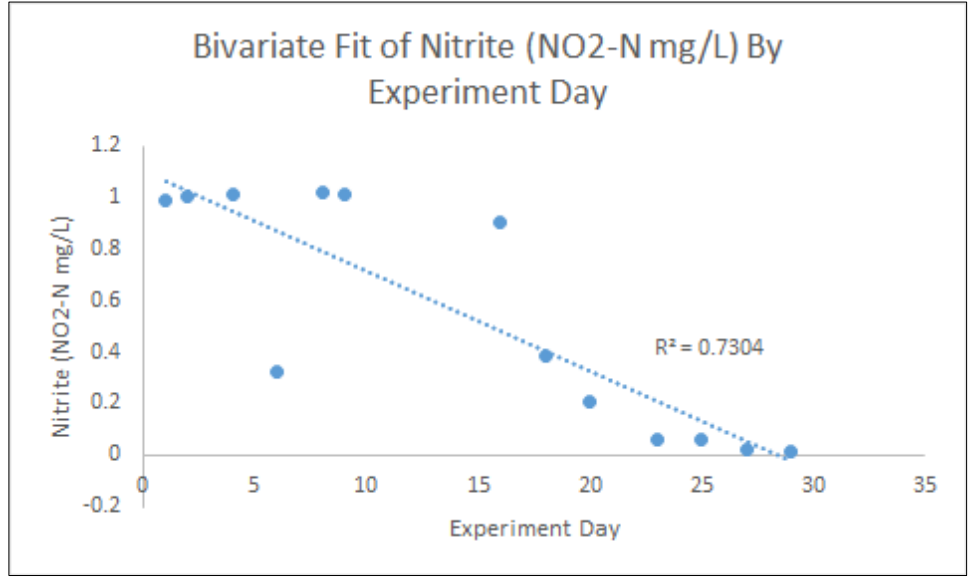

Figure 4. The correlation of nitrite to time shown in days. 


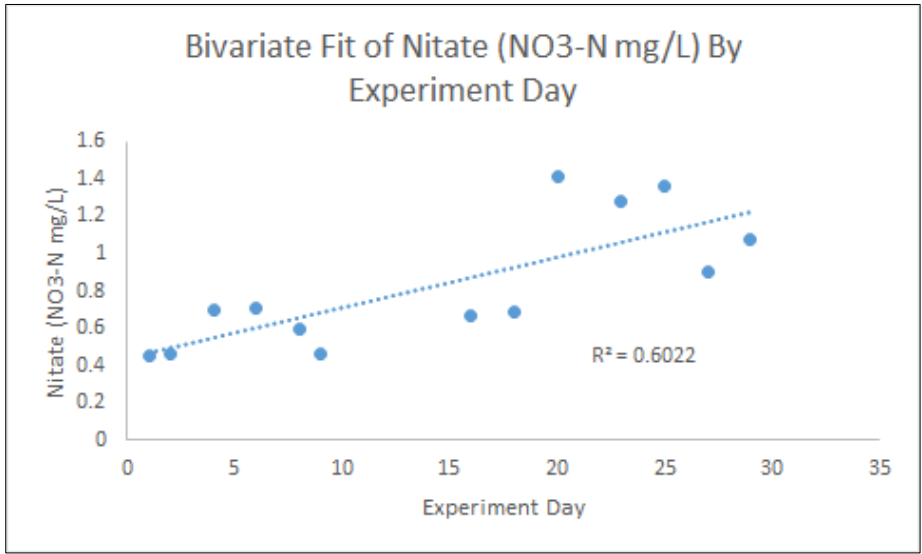

Figure 5. The correlation of nitate to time shown in days.

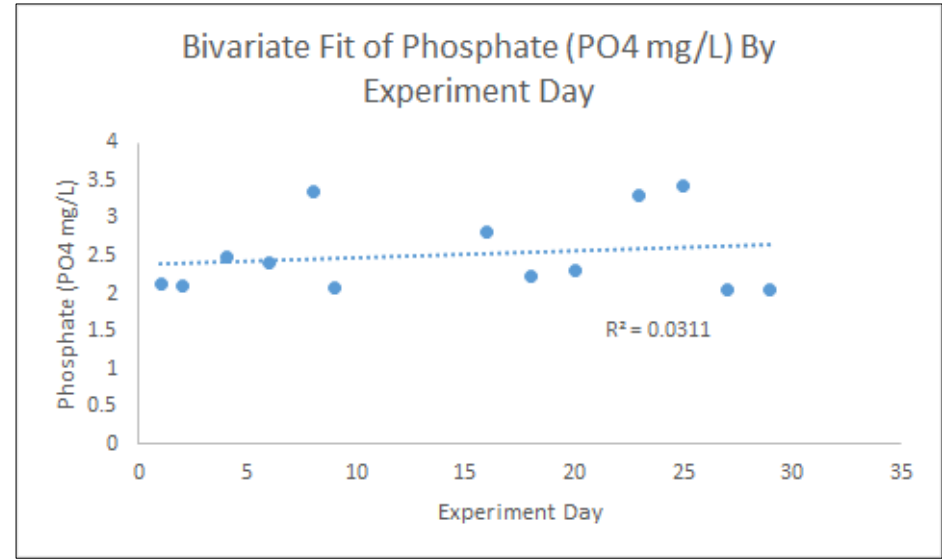

Figure 6. The correlation of phosphate to time shown in days.

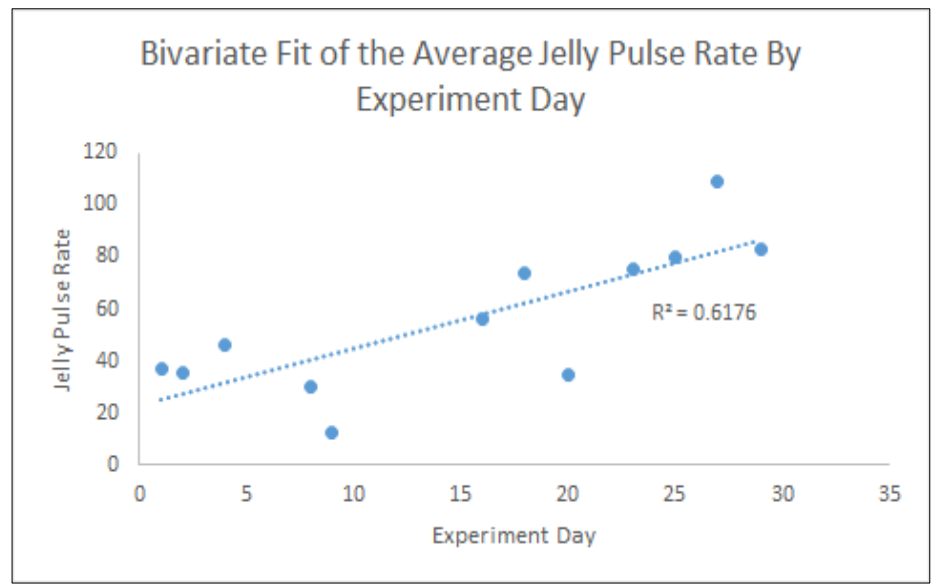

Figure 7. The correlation of the average jelly pulse to time shown by days.

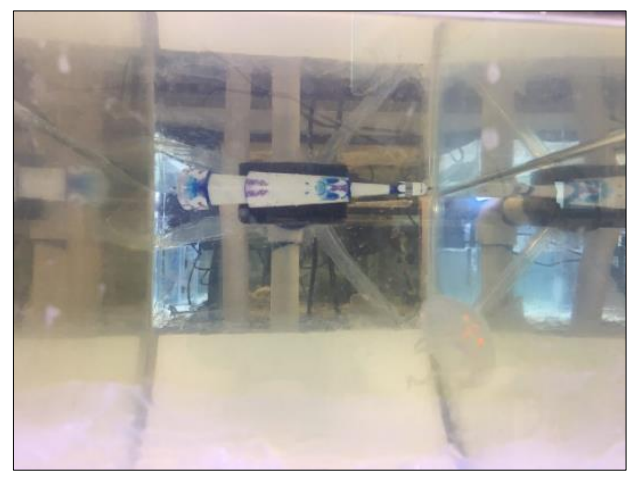

Figure 8. Shows the set up design of the spray bar that prevents the jellies being sucked into the pump. 


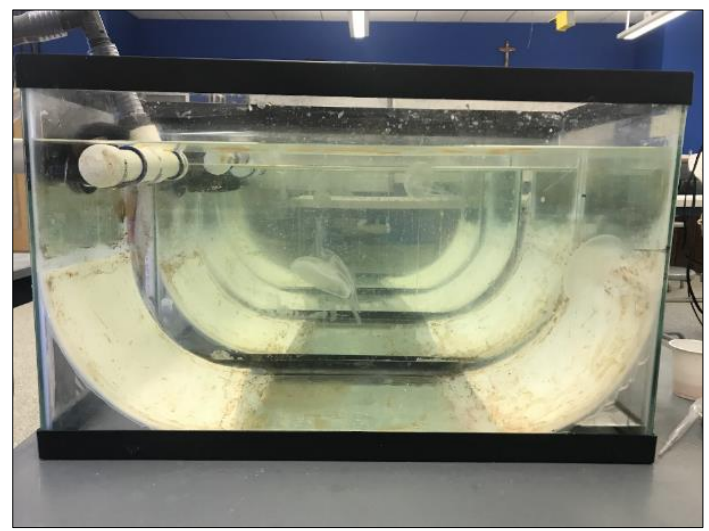

Figure 9. Depicts a side profile few of the tank.

\section{3- Discussion}

Initially the water flow was too high and caused some jellies to die by becoming stuck to the drain screen. However, once we adjusted our system flow rate, no additional jellies died. The pulsing rate of each jelly was observed and recorded. Ammonia, nitrite, nitrate, and phosphate were also measured. Ammonia had a significant decrease as the experiment progressed $(\mathrm{R} 2=0.455, \mathrm{~F} 1,11=9.195, \mathrm{P}=0.011$, Figure 1$)$. The decrease of ammonia is believed to be caused by bacteria converting the ammonia into nitrite. Also across the time it took to complete this experiment multiple jellies died (went from 4 to 1 jelly).

Nitrite had a significant decrease as well $(\mathrm{R} 2=0.730, \mathrm{~F} 1,11=29.800, \mathrm{P}=0.0002$, Figure 2$)$. The reason believed that the nitrite decreased is that the nitrite is converted into nitrate by nitrifying bacteria, which less harmful to the jellies in the tanks. Also over the course of the experiment some jellies died which caused the nitrite to decrease since there was less ammonia in the tank.

Nitrate had a significant increase $(\mathrm{R} 2=0.602, \mathrm{~F} 1,11=16.650, \mathrm{P}=0.002$, Figure 3$)$. Nitrate is believed to have increased because ammonia gets converted into nitrite and then nitrate. Nitrate is a byproduct of all the waste that is broken down in the tank. The only way to lower the nitrate levels would be a water change (water changes were done on each Sunday) therefore by the end of the week the nitrate levels would be at their highest.

Phosphate did not significantly change over the duration of the experiment $(\mathrm{R} 2=0.031, \mathrm{~F} 1,11=0.353, \mathrm{P}=0.564$, Figure 4). Phosphate can enter the water through various ways including from uneaten food to chemicals used to balance the jelly tanks. The schedule required specific management of feeding and testing which is believed to be why the phosphate levels are not significantly different.

The jelly pulse rate increased over the experiment $(\mathrm{R} 2=0.618, \mathrm{~F} 1,10=16.148, \mathrm{P}=0.002$, Figure 5$)$. The jellies were in an environment where they were only moved once a week on Sundays to due the water change. Thus, they did not have an increase in stress levels.

\section{4- Conclusion}

Jellies are difficult to maintain because they require a constant flow of water and need to be in a tank with no corners. Moon Jellies are also very sensitive to water changes and need a stable water chemistry in order to obtain prime health conditions; this includes having water temperature between 50 to 70 degree Fahrenheit range and a pH level of around eight. It was very important that the whole system ran smoothly because if something didn't run properly it could harm the jellies. Many specialty-designed tanks for jellies are extremely expensive for just one tank, while we had to make four tanks. We choose jellies because we wanted a challenge as well as to increase our knowledge and love of jellies. Overall, our "bargain" jelly tank build was a success after flow rates were properly adjusted. Jelly stress/health (measured as pulse rate over 5 minutes) increased over the month. We recommend that other undergraduate research programs with small budgets not shy away from doing research which would normally require expensive equipment! With a little ingenuity and hard work, so much is possible!

\section{5- Acknowledgements}

We would like to express our deepest appreciation to all those who provided us with the ability to perform this research project. A special thanks goes to the Saint Francis University, Biology Department for helping to fund this project.

\section{6- Ethical Approval}

All applicable international, national, and/or institutional guidelines for the care and use of animals were followed. 


\section{7- References}

[1] Gemmell, Brad J., Hernando P. Bacosa, Zhanfei Liu, and Edward J. Buskey. "Can Gelatinous Zooplankton Influence the Fate of Crude Oil in Marine Environments?” Marine Pollution Bulletin 113, no. 1-2 (December 2016): $483-487$. doi:10.1016/j.marpolbul.2016.08.065.

[2] Imbler, S. Jellyfish "Gooeyness" Could Be a Model for Self-Healing Robots. Scientific American. (2016). Retrieved 4 November 2016, from https://www.scientificamerican.com/article/jellyfish-gooeyness-could-be-a-model-for-selfhealing-robots/.

[3] How Do Oil Spills out at Sea Typically Get Cleaned Up? | response.restoration.noaa.gov. (2016). Response.restoration.noaa.gov. Retrieved 4 November 2016, from http://response.restoration.noaa.gov/about/media/ how-do-oil-spills-out-sea-typically-get-cleaned.html.

[4] How Jellyfish Break Down Oil After a Spill. (2017). Ocean Portal | Smithsonian. Retrieved 12 September 2017, from http://ocean.si.edu/ocean-news/how-jellyfish-break-down-oil-after-spill. 